Research Paper Vol 2, No 2, Tahun 2020

\title{
Kajian Penyebab Kerusakan Door Packing pada Tabung Sterilizer Menggunakan Metode Root Cause Analysis (RCA) di Sungai Kupang Mill
}

\author{
Idad Syaeful Haq ${ }^{1}$, Maulana Ahsan Purba ${ }^{1}$ \\ ${ }^{1}$ Program Studi Teknologi Pengolahan Sawit, Institut Teknologi Sains Bandung \\ Email:idadshaq@itsb.ac.id; maulanaahsanpurba@gmail.com
}

\begin{abstract}
Abstrak
Kajian kerusakan door packing pada tabung sterilizer didasari karena sering terjadinya kerusakan atau pecahnya door packing pada pintu tabung sterilizer di beberapa Pabrik Kelapa Sawit (PKS). Kerusakan ini dapat mengganggu jalannya proses produksi karena harus diperbaiki dengan diganti saat itu juga. Kajian ini bertujuan untuk mengetahui seberapa sering masalah ini terjadi, mengetahui penyebab masalah yang terjadi, mengetahui seberapa besar dampak yang ditimbulkan dari masalah ini, dan menemukan solusi dari masalah yang terjadi. Adapun metode yang digunakan untuk mengidentifikasi permasalahan ini adalah dengan menggunakan RCA, yaitu metode yang digunakan untuk mencari penyebab kegagalan suatu sistem atau mesin dengan menelusuri persoalan dimulai dari akar atau dasar permasalahan. Hasil dari kajian ini adalah diketahuinya penyebab dari kerusakan door packing di stasiun sterilizer, yaitu: safety valve tidak bekerja dengan baik, kondisi pintu sudah tidak sejajar dengan tabung, alur door packing sudah tidak mengikat (lebar). Dari beberapa penyebab kerusakan, solusi yang diberikan adalah dengan melakukan penyetelan ulang safety valve, penyetelan ulang alur pintu, melakukan penggantian pintu pada pintu yang memiliki alur door packing sudah tidak mengikat (melebar), dan melakukan perawatan dengan menambahkan monitoring book di stasiun sterilizer.
\end{abstract}

Kata Kunci: door packing, sterilizer, Root Cause Analysis (RCA), Pabrik Kelapa Sawit (PKS) 


\section{Research Paper Vol 2, No 2, Tahun 2020}

\section{Pendahuluan}

\subsection{Latar Belakang}

Pabrik Kelapa Sawit (PKS) merupakan industri yang bertanggung jawab dalam pengolahan TBS yang kemudian dihasilkan Crude Palm Oil/Palm Kernel Oil (CPO/ PKO). Proses pengolahan TBS hingga menjadi CPO di PKS dilakukan melalui beberapa tahapan atau disebut dengan istilah stasiun. Salah satu stasiun di PKS yang berfungsi melakukan perebusan TBS adalah stasiun rebusan (sterilizer). Tujuan utama stasiun sterilizer ini, antara lain menonaktifkan enzim lipase yang dapat menyebabkan kenaikan Free Fatty Acid (FFA), melunakkan berondolan agar daging buah mudah terlepas dari nut, serta mengurangi kadar air pada nut sehingga meningkatkan efisiensi pemecahan nut.

Stasiun sterilizer terdiri dari beberapa komponen peralatan, salah satu di antaranya adalah doorpacking yang terdapat pada pintu tabung rebusan. Fungsi doorpacking adalah agar uap saat proses perebusan tidak keluar melalui celah pintu. Apabila uap keluar melalui celah pintu teresebut. maka tekanan uap di dalam tabung sterilizer tidak stabil. Ketidakstabilan tekanan ini akan berdampak buruk pada kualitas hasil perebusan buah. Kerusakan atau pecahnya doorpacking tabung sterilizer merupakan permasalahan yang sering terjadi di PKS. Hal ini didasarkan kepada pengamatan dan hasil diskusi dengan para karyawan pabrik. Permasalahan ini tentu saja dapat merugikan PKS, kerugian yang ditimbulkan seperti mengganggu jalannya proses produksi, menurunkan throughput atau hasil produksi, menambah ongkos produksi, serta dapat menimbulkan kecelakaan kerja bagi para operator atau karyawan.

Permasalahan ini haruslah segera diselesaikan dengan mencari penyebabnya dengan benar. Ada beberapa metode yang bisa digunakan dalam mengidentifikasi penyebab dari masalah ini. Salah satu metode untuk mengetahui penyebabnya yaitu dengan menggunakan metode atau alat yang disebut Root Cause Analysis (RCA), yaitu metode yang digunakan untuk dapat mengetahui kegagalan dari suatu sistem ataupun mesin. Metode ini bekerja dengan meninjau penyebab kegagalan dari hal yang paling dasar dan kemudian di kelompokkan masing-masing penyebab agar lebih mudah untuk mengetahui penyebab utama dari kegagalan ini.

\section{B. Tujuan Penelitian}

Adapun tujuan dari penelitian ini adalah: mengetahui seberapa sering masalah ini terjadi, mengetahui penyebab masalah yang terjadi, mengetahui seberapa besar dampak yang ditimbulkan dari masalah ini, dan menemukan solusi dari masalah yang terjadi.

\section{DASAR TEORI}

\subsection{Stasiun Perebusan (Sterilizer)}

Sterilisasi merupakan proses perebusan terhadap TBS. TBS yang telah berada di dalam lori dipanaskan dengan menggunakan uap jenuh (saturated steam) pada tekanan dan suhu tinggi di dalam ketel rebusan yang disebut sterilizer (MCMD, 2013). Sterilizer ini berupa bejana silinder mendatar dengan pintu pada kedua ujungnya. Penyaluran panas dari steam ini dilakukan secara konveksi dan konduksi. Perpindahan panas secara konveksi, yaitu perpindahan panas dari steam ke fruitlet. Sedangkan perpindahan panas secara konduksi yaitu uap masuk ke dalam kernel dan lapisan dalam dari TBS. Sterilisasi ini dilakukan dengan sistem tiga puncak (tripple peak).

Ada beberapa tipe pada stasiun sterilizer, tipetipe ini dikelompokkan berdasarkan jumlah tabung dan kapasitas produksi pabrik.

(a) Stasiun sterilizer 4 tabung: tipe 4 tabung ini biasanya didesain pada pabrik berkapasitas 60 hingga 80 ton/jam.

(b) Stasiun sterilizer 3 tabung: tipe 3 tabung ini biasanya didesain pada pabrik berkapasitas 45 ton/jam.

(c) Stasiun sterilizer 2 tabung: tipe 2 tabung ini biasanya didesain pada pabrik berkapasitas 30 ton/jam. Stasiun sterilizer juga memiliki kapasitas yang berbeda tiap tipe nya. Kapasitas stasiun sterilizer merupakan kemampuan sterilizer dalam menyiapkan TBS yang sudah direbus dalam satuan waktu (ton/jam) yang dihitung dengan rumus: $S \times N \times C$

\section{Rumus Kapasitas Sterilizer $=$ $t \times 60$ menit}

Sterilizer berfungsi dan memiliki tujuan:

a) menonaktifkan enzim lipase yang dapat menyebabkan kenaikan FFA (Free Fatty Acid);

b) melunakkan berondolan untuk memudahkan pelepasan/pemisahan daging buah dari nut di digester;

c) memudahkan proses pemisahan molekulmolekul minyak dari daging buah (stasiun 


\section{Research Paper Vol 2, No 2, Tahun 2020}

press) dan mempercepat proses pemurnian minyak (stasiun Klarifikasi); dan

d) mengurangi kadar air biji sawit (Nut) sampai < 20\%, sehingga meningkatkan efisiensi pemecahan biji sawit (Nut).

\subsection{Tabung Sterilizer}

Peralatan utama pada stasiun Sterilizer adalah tabung sterilizer. Hal penting pada tabung sterilizer adalah pada bagian pintu (penutup bejana). Bagian pintu ini merupakan bagian yang berfungsi untuk memasukkan buah sawit belum direbus dan mengeluarkan buah sawit hasil persebusan. Berikut gambar dari stasiun sterilizer dan letak posisi door packing pada pintu tabung sterilizer.

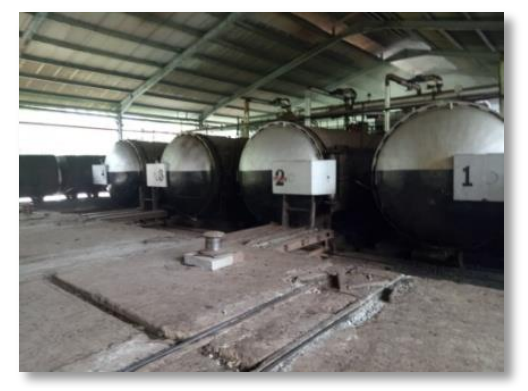

Gambar 1. Layout steriliser

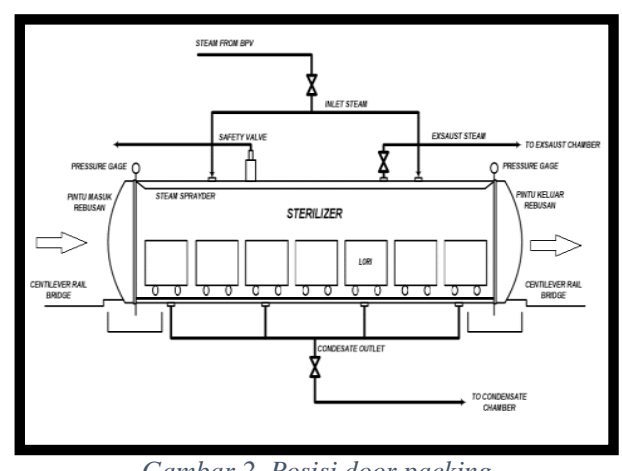

Gambar 2. Posisi door packing

\section{Root Cause Analysis (RCA)}

Root Cause Analysis (RCA) adalah metode yang digunakan untuk dapat mengetahui kegagalan dari suatu sistem ataupun mesin. Metode ini bekerja dengan meninjau penyebab kegagalan dari hal yang paling dasar dan kemudian dikelompokkan masing-masing penyebab agar lebih mudah untuk mengetahui penyebab utama dari kegagalan ini (Vorley, 2008). Beberapa tools yang bisa digunakan untuk mengetahui akar suatu masalah adalah: 5 Whys, diagram tulang ikan (fishbone diagram). Fishbone diagram (diagram sering juga disebut Cause and Effect Diagram atau Ishikawa Diagram.

Diagram ini diperkenalkan oleh Dr. Kaoru Ishikawa, seorang ahli pengendalian kualitas dari
Jepang, sebagai satu dari tujuh alat kualitas dasar (7 basic quality tools). Diagram tulang ikan digunakan ketika ingin mengidentifikasi kemungkinan penyebab masalah, serta digunakan terutama ketika sebuah tim cenderung berpikir kepada rutinitas kegiatan (Tague, 2005).

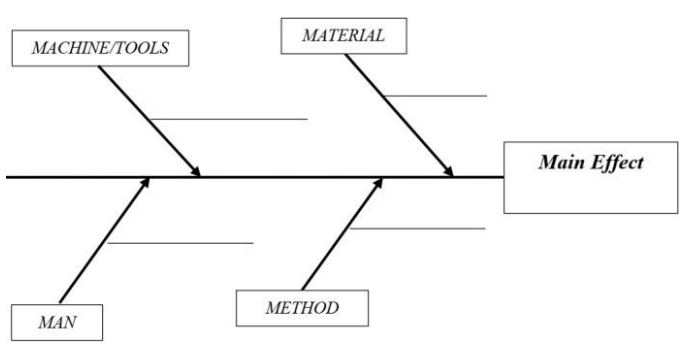

Gambar 3. Standar Fishbone Diagram

Analisis 5 Whys adalah suatu pendekatan terstruktur dimana diajukan pertanyaan mengapa (why) secara berulang kali. Pengulangan hingga lima kali pertanyaan mengapa (why) ini untuk memahami penyebab akar suatu masalah. Pemahaman terhadap akar suatu masalah akan menghasilkan tindakan korektif yang efektif untuk mengurangi insiden itu terjadi kembali. Pada tahap ini nantinya hasil yang diperoleh akan dilanjutkan untuk diolah pada tahap fishbone diagram (Vorley, 2008).

Tabel 1. Perbedaan Metode 5 Whys dan Diagram Tulang Ikan

\begin{tabular}{|l|l|l|}
\hline Metode & \multicolumn{1}{|c|}{ Kelebihan } & \multicolumn{1}{|c|}{ Kekurangan } \\
\hline 5 Whys & $\begin{array}{l}\text { Dapat langsung } \\
\text { menemukan } \\
\text { penyebab }\end{array}$ & $\begin{array}{l}\text { Butuh } \\
\text { Narasumber atau } \\
\text { sumber yang } \\
\text { jelas }\end{array}$ \\
\hline $\begin{array}{l}\text { Diagram } \\
\text { tulang } \\
\text { ikan }\end{array}$ & $\begin{array}{l}\text { Mudah dipahami } \\
\text { dengan } \\
\text { mengelompokkan } \\
\text { sebab dan akibat } \\
\text { serta ditampilkan } \\
\text { dengan gambar }\end{array}$ & $\begin{array}{l}\text { Butuh } \\
\text { dalam } \\
\text { pengelompokkan } \\
\text { penyebab }\end{array}$ \\
\hline
\end{tabular}

\section{METODE PENELITIAN}

\subsection{Lokasi Penelitian}

Penelitian ini dilaksanakan di PT. Sinar Kencana Inti Perkasa - Sungai Kupang Mill (SKPM) berlokasi di Desa Sungai Kupang, Kecamatan Kelumpang Hulu, Kabupaten Kotabaru, Provinsi Kalimantan Selatan.

\subsection{Tahapan Penelitian}

Alur kerja metode Root Cause Analysis (RCA) ini terdiri dari beberapa langkah yang harus dilakukan: 


\section{JVTI}

JURNAL VOKASI

\section{Research Paper Vol 2, No 2, Tahun 2020}

a. Mendefinisikan Masalah

Langkah ini adalah langkah awal yang harus dilakukan, sebelum mencari penyebab dan lainnya masalah haruslah didefinisikan terlebih dahulu agar memudahkan untuk langkah selanjutnya.

b. Mengumpulkan Data

Setelah masalah diketahui hal yang harus dilakukan selanjutnya yaitu mengumpulkan data yang bisa digunakan untuk mendalami masalah tersebut. Pengumpulan data dapat dilakukan dengan mengambil data langsung (data primer), meninjau data yang sudah tersedia yang berasal dari beberapa perlakuan yang telah terjadi (data sekunder), dan bisa juga dengan mewawancarai pihak-pihak yang terlibat dalam masalah tersebut. Data yang harus diketahui antara lain yaitu: sudah berapa lama masalah tersebut ada, dan dampak yang dirasakan dengan adanya masalah tersebut.

c. Identifikasi Penyebab yang Mungkin Terjadi

Dalam langkah ini hal yang harus dilakukan yaitu: menjabarkan urutan kejadian yang mengarah kepada masalah, pada kondisi bagaimana masalah tersebut terjadi, dan adakah masalah-masalah lain yang muncul seiring dengan masalah utama.

d. Identifikasi Akar Masalah

Langkah ini merupakan langkah yang harus dilakukan dengan sangat teliti dan kritis. untuk dapat mengetahui akar masalah ada beberapa tools yang bisa digunakan seperti: 5 Whys, diagram tulang ikan (Fishbone diagram/ ishikawa).

e. Ajukan dan Implementasikan Solusi

Setelah keempat langkah sebelumnya telah didapatkan, langkah terakhir yang harus dilakukan yaitu dengan mengajukan solusi yang dapat diimplementasikan dengan efektif dan efisien.

\section{PEMBAHASAN}

\subsection{Identifikasi Masalah dan Pengamatan pada Door Packing Tabung Sterilizer}

Saat tabung sterilizer beroperasi pada stasiun sterilizer, ditemukan persoalan sering terjadinya kerusakan pada door packing. Akibat seringnya terjadi kerusakan pada door packing, hal ini akan mengganggu jalannya proses produksi. Proses produksi yang terganggu akan berdampak secara keseluruhan pada throuhgput atau hasil pengolahan buah sawit pada hari tersebut. Untuk mengetahui apakah di pabrik Sungai Kupang sering mengalami terjadi kerusakan pecahnya door packing pada tabung sterilizer.

Untuk mengetahui hal tersebut, dilakukan pengambilan data selama satu tahun terakhir, yaitu pada bulan Januari hingga Desember 2018 (data pengamatan terlampir pada Gambar 4). Pada tabung sterilizer terdapat 2 (dua) buah door packing, yaitu terpasang pada pintu masuk (inlet) dan pintu keluar (outlet). Di PKS Sungai Kupang memilikui 4 tabung sterilizer, sehingga jumlah keseluruhan terdapat 8 (delapan) door packing yang digunakan selama beroperasinya tabung sterilizer.

Data pergantian door packing ditunjukkan pada Gambar 4, serta disajikan juga Tabel 2 yang berisi keterangan pergantian kerusakan setiap tabungnya. Berikut data pergantian door packing tabung sterilizer yang terjadi di pabrik Sungai Kupang selama kurun waktu 1 (satu) tahun terakhir (Januari-Desember 2018).

Berdasar Gambar 4, terlihat jumlah (kuantitas) kerusakan door packing pada setiap tabung sterilizer. Data pada Tabel 2 menyajikan jumlah penggantian door packing pada setiap tabung.

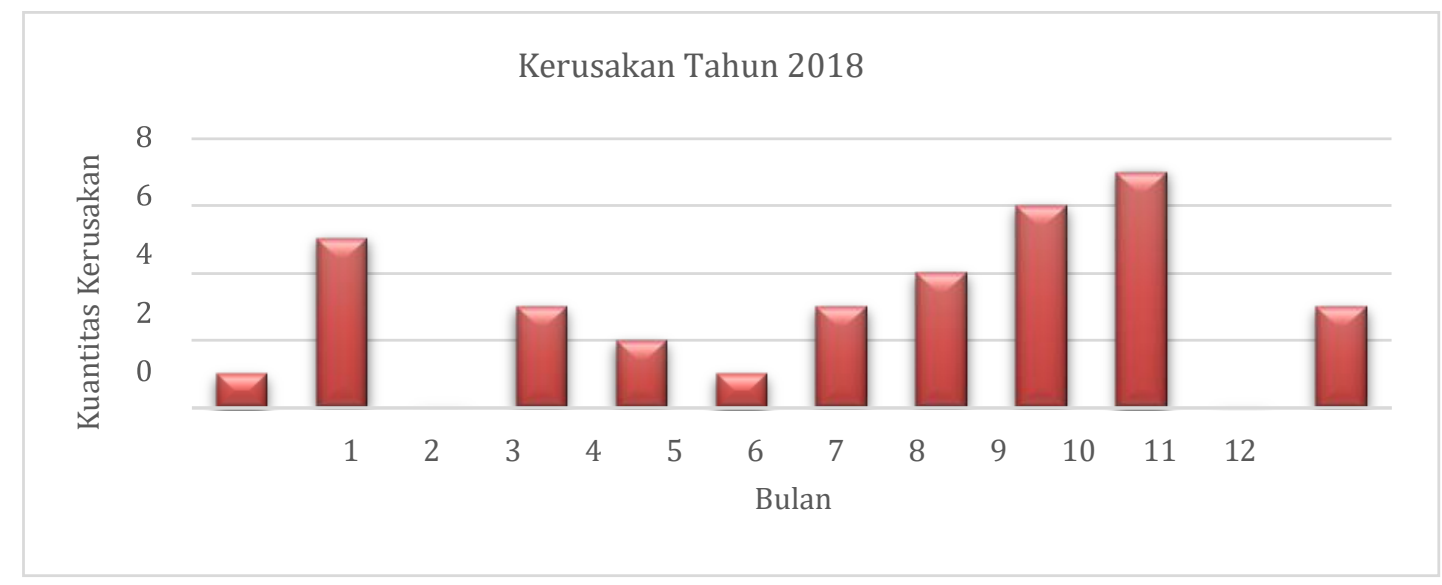

Gambar 4. Grafik pergantian door packing tahun 2018 


\section{Research Paper Vol 2, No 2, Tahun 2020}

Terlihat pada tabung sterilizer nomor 1 dan 4 merupakan tabung yang sering mengalami kerusakan, yaitu tabung sterilizer nomor 2 mengalami 11 kali kerusakan, kemudian tabung nomor 2 mengalami 7 kali kerusakan dan tabung nomor 3 mengalami 6 kali kerusakan. Pada tahun 2019 terjadi juga beberapa kerusakan door packing, berikut data pada reservation list hingga bulan April 2019.

Tabel 2. Data pergantian door packing pada tahun 2019

\begin{tabular}{|l|l|c|}
\hline No. & Bulan & Quantity pergantian \\
\hline 1. & Januari & 1 \\
\hline 2. & Februari & 2 \\
\hline 3. & Maret & 5 \\
\hline 4. & April & 1 \\
\hline \multicolumn{3}{|c|}{ Total } \\
\hline \multicolumn{2}{|c|}{ Sumber: SKPM Reservation List, SAP ; MB25) }
\end{tabular}

\subsubsection{Kemungkinan Penyebab Kerusakan dan Kegagalan Stasiun Sterilizer}

Untuk dapat mengetahui penyebab pasti dari kerusakan suatu sistem, ada baiknya terlebih dahulu dituliskan kemungkinan penyebab yang dapat terjadi. Hal ini bertujuan untuk membantu mempermudah kerja dalam melakukan pengamatan dan pengambilan data di lapangan. Setelah kemungkinan penyebab ditulis, selanjutnya dilakukan pengamatan satu persatu kemungkinan penyebab kerusakan tersebut. Hal ini diperlukan untuk memastikan apakah kemungkinan penyebab tersebut benar merupakan penyebab kerusakan atau bukan. Ada beberapa kemungkinan penyebab kerusakan dan kegagalan dari masing-masing permasalahan tersebut, di antaranya:

a) Ketidaktercapaian kebutuhan uap dalam proses pengolahan

Ketidaktercapaian kebutuhan uap ini bisa terjadi dari beberapa kemungkinan penyebab, di antaranya yaitu: kurangnya supply bahan bakar boiler dan kebocoran dari pipa steam inlet menuju tabung sterilizer.

b) Kerusakan atau pecahnya door packing pada tabung sterilizer

Kerusakan atau pecahnya door packing ini bisa terjadi dari beberapa kemungkinan penyebab, di antaranya yaitu: safety valve tidak bekerja dengan baik, alur packing sudah tidak mengikat, draine tersumbat, exhaust tidak berjalan dengan baik, kondisi pintu sudah tidak sejajar terhadap tabung, kondisi pintu melengkung, pemasangan packing salah, pengoperasian mesin yang tidak benar, masuknya benda asing menyumbat strainer (Tabel 4).
Berdasar beberapa kemungkinan penyebab kerusakan door packing tabung sterilizer di atas, kemudian satu persatu dilakukan pengamatan, mengecek apakah kemungkinan tersebut benar meruapakan penyebab kerusakan, jika benar dapat dicarikan solusi yang tepat dalam menanganinya. Setelah masing-masing kemungkinan penyebab tersebut diamati dan didapatkan penyebab pasti kerusakannya, barulah masuk ke langkah selanjutnya, yaitu mencari data dan mengamati mengapa hal tersebut dapat terjadi. Beberapa solusi yang tepat dapat dilakukan untuk menangani masalah tersebut.

\subsection{Identifikasi Penyebab Kerusakan Door Packing pada Tabung Sterilizer}

Setelah penyebab kerusakan door packing ini sudah diketahui, maka langkah selanjunya adalah pengamatan dan pencarian data mengenai faktor-faktor penyebab kerusakan ini. Untuk memudahkan menentukan penyebabnya, faktorfaktor kemungkinan penyebab kerusakan dikelompokkan kembali agar dipahami dengan mudah. Kemudian ditelusuri satu per satu beberapa kemungkinan penyebab. Berikut penyabab pasti kerusakan yang telah diperoleh berdasar beberapa hasil pengamatan:

\section{A) Safety valve tidak bekerja dengan baik} Penyebab pertama kerusakan door packing pada tabung sterilizer adalah safety valve tidak bekerja dengan baik, artinya safety valve tidak bekerja pada setting-an seharusnya. Setingan safety valve di stasiun sterilizer adalah pada tekanan 3,2 barg. Apabila tekanan uap yang berada di dalam tabung melebihi 3,2 barg, maka safety valve secara otomatis akan membuka untuk mengurangi tekanan yang di dalam tabung. Hal ini ditandai dengan keluarnya uap melalui saluran pipa blow off safety valve. Apabila tekanan uap di dalam tabung melebihi 3,2 barg dan kondisi safety valve tidak membuka, maka ada masalah pada safety valve tersebut.

Biasanya masalah yang terjadi adalah setingan safety valve sudah tidak tepat/akurat lagi. Hal seperti ini yang terjadi pada kondisi safety valve tabung rebusan nomor 1 . Kejadian ini ditandai dengan tidak keluarnya uap pada pipa blow off safety valve nomor 1, berbeda pada kondisi safety valve di tabung lainnya yang mengeluarkan uap pada tekanan di dalam tabung diatas 3,2 barg.

Data ini didapatkan pada pengamatan langsung di stasiun sterilizer selama 1 bulan di bulan Maret. Pada bulan Maret terjadi 4 kali kerusakan 


\section{Research Paper Vol 2, No 2, Tahun 2020}

pecah packing pada tabung sterilizer nomor 1 . Pecah packing tersebut terjadi setelah tekanan uap di dalam tabung melebihi 3,2 barg dan ditandai dengan tidak keluarnya uap pada pipa blow off safety valve tabung nomor 1, sedangkan tabung lainnya uap keluar dari pipa blow off safety valve. Pada kondisi seperti ini harus diambil solusi dengan melalukan penstingan ulang (resetting) pada safety valve agar safety valve dapat membuka pada tekanan lebih dari 3,2 barg.

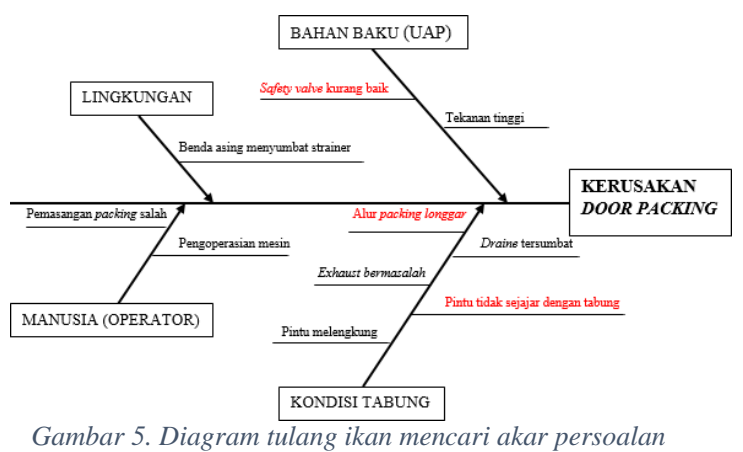

B) Kondisi pintu sudah tidak sejajar terhadap tabung

Penyebab kedua kerusakan door packing pada tabung sterilizer adalah kondisi pintu tidak sejajar terhadap tabung. Penyebab ini ditandai dengan keluarnya uap melalui celah pintu pada saat sedang terjadi penaikan dan penahan uap di dalam tabung. Dampak yang ditimbulkan dari kebocoran ini adalah dapat diindikasikan sebagai pemicu pecah door packing. TBS yang keluar dalam kondisi kurang matang atau mentah akibat tekanan di dalam tabung tidak tercapai. Langkah yang harus diambil adalah dengan melalukan pensetingan pintu agar dapat sejajar kembali dengan tabung.
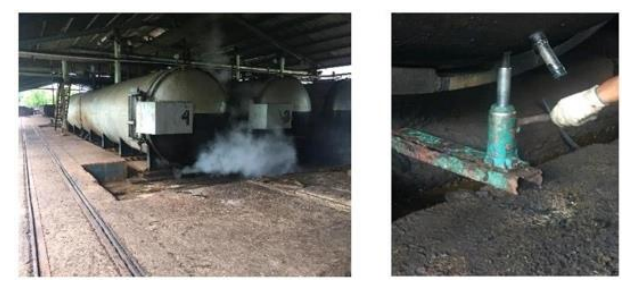

Gambar 6. Dampak dan solusi kondisi pintu yang tidak sejajar

\section{C) Alur door packing sudah tidak mengikat (lebar)}

Penyebab kedua kerusakan door packing pada tabung sterilizer adalah alur door packing sudah tidak mengikat (melebar). Penyabab ini ditandai dengan pada saat pemasangan door packing harus menggunakan kain majun (kain perca) sebagai pelapis packing. Fungsi pemasangan kain majuan ini adalah agar packing dapat terpasang dengan ketat/rapat pada pintu. Tetapi cara ini belum efektif, karena seiring waktu kain majun yang digunakan akan rapuh dan hancur karena akan terkena air kondensat dan juga tekanan dan temperatur yang realtif tinggi di dalam tabung rebusan.

Jika kain majun tersebut mengalami kehancuran, maka packing akan mengendor. Kondisi inilah yang membuat packing pecah karena kendor dan tidak menempel dengan rapat dengan pintu. Kejadian ini benar terjadi, saat dilakukan pengamatan di lapangan pada bulan maret terdapat 4 kali pecah door packing pada tabung nomor 1 di pintu keluar (outlet).

Titik pecah door packing selalu terjadi pada posisi bagian bawah pintu, dimana alur packing pada door packing sudah melebar, sehingga diberi pelapis kain majun. Cara ini tidak efektif jika diterapkan secara terus-menerus untuk mengatasi masalah tersebut. Dampak yang ditimbulkan apabila cara ini terus dilakukan adalah akan sering terjadi pecah door packing, karena kain majun tersebut tidak dapat bertahan lama pada kondisi lembab, tekanan tinggi dan temperatur tinggi.

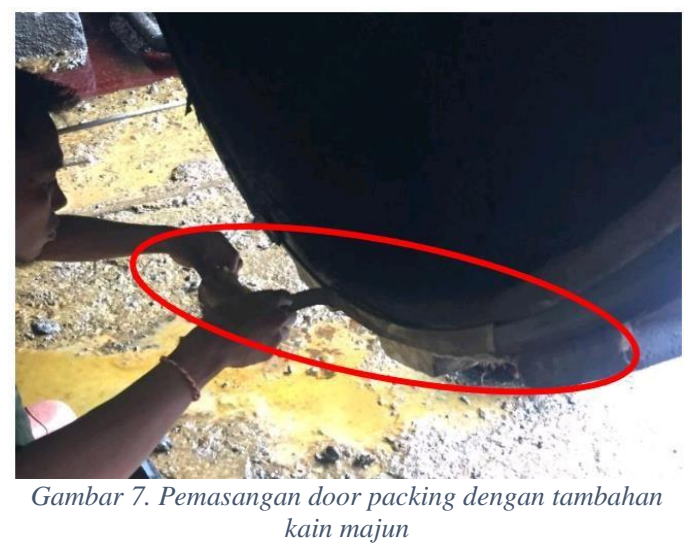

\subsection{Dampak Kerusakan Door Packing Tabung Sterilizer}

Setiap permasalahan yang timbul dalam sesuatu sistem atau keadaan pastilah akan menimbulkan dampak yang dapat merugikan. Dampak yang ditimbulkan dapat berakibat kerugian kecil hingga besar. Dalam permasalahan ini ada beberapa dampak yang ditimbulkan, berikut beberapa dampak yang dapat timbul dari permasalahan kerusakan door packing tabung sterilizer ini: (1)mengganggu jalannya proses produksi, (2)menurunkan hasil pengolahan (throughput), (3)menimbulkan kecelakaan kerja, dan (4)menambah ongkos produksi. 


\section{Research Paper Vol 2, No 2, Tahun 2020}

\subsubsection{Implementasi Solusi}

Untuk mengatasi masalah yang terjadi haruslah diambil langkah yang terbaik dalam penanganannya. Pada masalah yang terjadi sekarang yaitu kerusakan door packing pada tabung sterilizer ada beberapa langkah penanganan masalah yang paling efektif guna menjaga dan meminimalkan kerusakan tersebut. Adapun solusi yang bisa dilakukan adalah:

\section{a) Penggantian pintu}

Pergantian pintu pada tabung sterilizer bukanlah suatu hal mudah. Haruslah dilakukan pengamatan terlebih dahulu apakah pintu tersebut dapat diperbaiki ataupun memang harus dilakukan pergantian. Dalam kasus ini kondisi pintu rebusan pada tabung nomor 1 sudah sebaiknya dilakukan penggantian. Hal ini dilihat dari kondisi fisik pintu yang sudah tidak baik pada kondisi alur door packing yang sudah lebar. Akibatnya sering terjadi pecah packing pada pintu tersebut dan pada posisi dimana kondisi alur packing sudah lebar. Apabila kondisi alur packing sudah melebar, maka door packing pun tidak dapat terpasang dengan baik, door packing akan kendur dan tidak menempel dengan rapat pada tabung. Hal ini lah yang dapat membuat door packing pecah.

Kejadian ini sudah terbukti dari hasil pengamatan selama sebulan penuh di bulan Maret, yang mana terjadi 4 kali pecah door packing pada pintu tabung sterilizer nomor $1 \mathrm{di}$ bagian pintu keluar (outlet). Pada pintu inilah alur door packing tersebut sudah melebar. Cara yang paling efektif untuk mengatasi masalah tersebut adalah dengan mengganti pintu tersebut. Penggantian ini bisa dilakukan dengan budgeting yang dilakukan setiap unit PKS setiap setahun sekali. Apabila langkah ini tidak terealisasi maka akan menjadi tugas besar yang akan terus dialami yaitu pecah door packing yang dampaknya sangatlah besar, seperti dapat menurunkan throuhput pabrik (ketercapaian hasil pengolahan), kecelakaan kerja, mengganggu proses produksi, dan menambah ongkos produksi.

b) Perawatan dengan menggunakan monitoring book

Solusi kedua yang dapat di aplikasikan untuk menangani permasalahan kerusakan door packing pada tabung sterilizer adalah dengan pengadaan monitoring book kerusakan pecah packing. Tujuan dari monitoring book ini adalah sebagai salah satu bentuk perawatan. Monitoring book ini dapat digunakan apabila ada kerusakan pecah packing, setelah packing diperbaiki atau diganti oleh operator stasiun maka selanjutnya operator dapat menuliskannya di buku ini.

Manfaat dari buku ini adalah sebagai history apabila terus terjadi kerusakan ini dan mempermudah perbaikan. Departemen yang bertanggung jawab dalam perawatan stasiun sterilizer ini tidak hanya departemen maintanance, tetapi departemen proses juga berperan dalam membantu perawatan stasiun tersebut. Adapun informasi atau format dari monitoring book dapat dilihat dari Tabel 5.

Format atau informasi dari monitoring book ini menjelaskan secara keseluruhan kondisi saat terjadi kerusakan door packing pada pintu tabung sterilizer. Hari dan tanggal menjelaskan kapan kerusakan ini terjadi dengan tujuan sebagai data kejadian kerusakan yang terjadi pada saat itu. Posisi tabung menjelaskan bagian tabung yang mengalami kerusakan dengan tujuan agar apabila tabung tersebut sering mengalami kerusakan maka ada sesuatu yang bermasalah pada tabung tersebut dan memudahkan pihak maintanance untuk melakukan perbaikan.

Waktu kerusakan dituliskan dengan tujuan kapan kerusakan terjadi dan untuk mengetahui nantinya seberapa lama waktu perbaikannya. Indikasi penyebab menginformasikan tentang bagaimana kondisi tabung saat sebelum terjadi kerusakan, hal ini depat mempermudah proses perbaikan nantinya bila kejadian ini sering terjadi di tempat yang sama. Waktu perbaikan bertujuan untuk mengetahui berapa lama perbaikan ini dilakukan dan akan berdampak kepada bertambahnya waktu pengolahan dan terlambatnya proses pengolahan.

\section{KESIMPULAN}

Penyebab kerusakan door packing pada tabung sterilizer dan penanganannya, yaitu: tahun 2018 terjadi sebanyaknya 35 kali kerusakan atau pecah door packing tabung sterilizer, kerusakan terjadi secara tidak merata setiap bulannya.

Pada tahun 2019 dimulai dari bulan JanuariApril terjadi sebanyak 9 kali kerusakan atau pecah door packing tabung sterilizer, terdapat beberapa dampak dari kerusakan door packing pada tabung sterilizer, yaitu: mengganggu jalannya proses produksi, menurunkan hasil pengolahan (throughput), menimbulkan kecelakaan kerja, dan menambah ongkos produksi.

Berhasil diidentifikasi penyebab kerusakan door packing pada tabung sterilizer, yaitu: safety valve 


\section{JVTI}

JURNAL VOKASI

\section{Research Paper Vol 2, No 2, Tahun 2020}

tidak berfungsi dengan baik, kondisi pintu sudah tidak sejajar dengan pintu, dan alur door packing sudah tidak mengikat (lebar). Solusi dalam menangani penyebab masalah ini adalah dengan melakukan pergantian pintu yang memiliki alur door packing sudah melebar, dan pengadaaan monitoring book yang bertujuan sebagai bentuk preventive maintanance di stasiun sterilizer.

\section{DAFTAR PUSTAKA}

Maulana Ahsan P., "Kajian Penyebab Kerusakan Door Packing pada Tabung Sterilizer
Menggunakan Metode Root Cause Analysis (RCA) di Sungai Kupang Mill”, Kota Deltamas 2019.

Standar Operasional Prosedur (SOP), Pengolahan Pabrik Kelapa Sawit PT. Smart. Tbk, 2013.

Voley, G., Mini Guide to Root Cause Analysis, Quality Management \& Training Limited, London, 2008. SKPM reservation list, SAP ; MB25

\section{LAMPIRAN TABEL}

Tabel 3. Pergantian door packing setiap tabung pada tahun 2018

\begin{tabular}{|c|c|c|c|c|c|c|c|c|c|}
\hline Tahun & Sterilizer-1 & \multicolumn{2}{|c|}{ Sterilizer-2 } & \multicolumn{2}{|c|}{ Sterilizer-3 } & \multicolumn{2}{|c|}{ Sterilizer-4 } & Jumlah \\
\hline \multirow{2}{*}{2018} & in & out & in & out & in & out & in & out & \multirow{2}{*}{35} \\
\cline { 2 - 9 } & 8 & 3 & 3 & 4 & 5 & 1 & 4 & 7 & 35 \\
\hline
\end{tabular}

Tabel 4. Gambar beberapa komponen kemungkinan penyebab kerusakan Door Packing

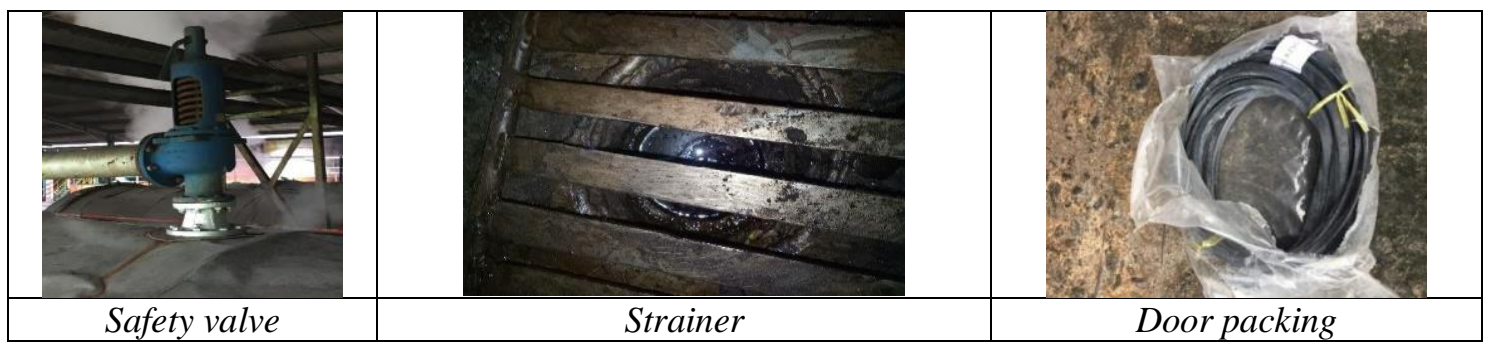

Tabel 5. Format Monitoring Book

\begin{tabular}{|c|c|c|c|c|c|}
\hline No. & $\begin{array}{c}\text { Hari, } \\
\text { Tanggal }\end{array}$ & Posisi Tabung & $\begin{array}{c}\text { Waktu } \\
\text { Kerusakan }\end{array}$ & Indikasi Penyebab & $\begin{array}{c}\text { Waktu } \\
\text { Perbaikan }\end{array}$ \\
\hline 1 & $\begin{array}{l}\text { Senin, } 10 \\
\text { juni } 2019\end{array}$ & $\begin{array}{l}\text { Tabung no. } 1 \\
\text { (outlet) }\end{array}$ & $\begin{array}{l}14.30 \\
\text { WITA }\end{array}$ & $\begin{array}{l}\text { Kebocoran pada pintu } \\
\text { keluar bagian bawah }\end{array}$ & 20 menit \\
\hline 2 & dst & & $\ldots$ & $\ldots \ldots \ldots \ldots \ldots$ & \\
\hline
\end{tabular}

